\title{
Library Services to Educationally Disadvantaged Students
}

\begin{abstract}
Librarians and Educational Opportunity Program (EOP) personnel were interviewed at eight urban college and university campuses to determine the extent to which their respective libraries have responded to educationally disadvantaged students. The study focused on four principal areas: relations between the library and the Educational $\mathrm{Op}$ portunity Program, library staff assignments, collections, and the provision of special services. A considerable range of service programming was discovered, and some of the factors which may account for the variation are discussed.
\end{abstract}

\section{I} N A 1971 Library Trends article entitled "The Role of the Academic Library in Serving the Disadvantaged Student," E. J. Josey identified four characteristics of an effective service program: staff members who are able to empathize with the special needs of disadvantaged students; the organization of a wide range of library resources; the implementation of innovative, action-oriented programs; and close and regular contact with the faculty who teach disadvantaged students. ${ }^{1}$ Other factors could also be cited, such as the institution's level of commitment to these students and the social consciousness of the library's staff and administration. These variables are much more difficult to ob-

Thomas W. Shaughnessy is associate dean of the School of Library Science at the University of Southern California, Los Angeles. The study on which this article is based was conducted in the spring of 1974 when the author was director of the Dana Library (Newark Campus) of Rutgers University. The investigation was funded by a grant from the Council on Library Resources. serve, much less describe, but they may indeed be determinants of the characteristics discussed by Josey.

The article mentioned above is one of the few substantive articles to address the question of academic library services to disadvantaged students. It is interesting to note that, in contrast, library literature virtually abounds with articles describing public library services to the urban poor, minority groups, and the educationally disadvantaged. The meager amount of literature on the academic side of the question, combined with the personal observations of a number of academic librarians, provided the stimulus for this research.

The basic hypothesis of the study was that academic libraries have not responded to their respective institutions' educationally disadvantaged students. These students are variously defined or described, but in the main they are individuals who are lacking in the educational background and communication and study skills necessary for successful college work. More often than not, they are members of various minority groups. Frequently such students are 
economically disadvantaged too, but the focus of this study is the educationally disadvantaged student.

\section{Sample Selection AND METHODOLOGY}

It would seem safe to assume that virtually every publicly supported institution of higher education has some students who are educationally disadvantaged. But in order to maximize the number of such students in a given institution, the population from which the sample was selected was limited to publicly supported urban colleges and universities. To attain a base which was somewhat broad and representative, eight institutions were selected from across the country. Two were located on the west coast, three in the midwest or middle Atlantic region, and three in the northeast. Southern colleges and universities were not included in the sample. The reason for this omission was due primarily to the application of the criterion of maximizing the number of educationally disadvantaged students in each institution. Rightly or wrongly, it was felt that the eight institutions selected met this criterion. Many other colleges and universities, such as those located in urban centers in the South, might also have been included. However, it is questionable whether the inclusion of the libraries of these institutions in the study would have any significant impact on its results.

The methodology employed in the study consisted primarily of interviews, accompanied by limited observation. It was originally proposed that questionnaires would be administered to a sample of educationally disadvantaged students to solicit their impressions and evaluations of academic library services as well as their suggestions as to how the respective libraries might better meet their needs. But this approach or technique had to be discarded for at least two reasons. First, there appeared to be no tactful way of identifying those students who were educationally disadvantaged from among the many students using the libraries in a given period. Second, administrators and faculty members assigned to work with these students were understandably reluctant to allow them to be the focus of still another study. Consequently, it was not possible to administer the questionnaires to assembled groups or classes of these students.

From a methodological point of view, the loss of student input considerably weakens the study. The questionnaires were seen as a means of corroborating or balancing the data collected by means of interviews, as well as of providing input from library users. But to a limited extent it was possible within the constraints imposed by the interview technique to "verify" the responses of the librarians interviewed. This was accomplished by comparing their answers or perceptions with those of a sample of administrators and counselors involved with programs designed to meet the special needs of educationally disadvantaged students. Interviews were conducted, therefore, first with librarians and then with Educational Opportunity Program personnel. (Programs for educationally disadvantaged students have various names or designations, depending on the institution. But for the purposes of this article, all such programs will be called Educational Opportunity Programs [EOP].) The number of librarians interviewed was twenty-four; and a total of thirteen EOP faculty and staff were interviewed.

It is encouraging to note that every library which was asked to participate in the study accepted the invitation. Some library directors were more enthusiastic than others, but that is to be expected. A few directors and several public service librarians appeared to be somewhat uneasy about the study, while others seemed to welcome the opportu- 
nity to discuss the topic. For both groups it is hoped that levels of social consciousness were raised.

\section{LIBRARY-EOP RELATIONS}

The study's findings concerning the relationship and frequency of contact between library and EOP staff tend to confirm many of the conclusions of the Whitbeck study, especially with respect to the isolation of librarians in many important collegial areas. ${ }^{2}$ In two instances, interviews revealed a virtual absence of contact between the two. But the majority of libraries visited had attempted to establish a dialogue with EOP faculty and staff. In one case the EOP staff failed to respond despite repeated attempts on the part of the library. The most frequent contact between library administrators and EOP directors seemed to occur at campuswide meetings of departmental deans and directors, meetings which typically afforded little more than an opportunity for them to introduce themselves or renew acquaintances.

Interviews with EOP faculty and staff revealed a range of views of the library which roughly paralleled the views of librarians toward EOP programs. A few seemed to be unaware of the library and its services. Others used the library for reserve readings but had not seriously considered the library as an important part of their teaching activities. And then there were those faculty who were very conscious of the library's potential role in educational programs for disadvantaged students. This latter group, however, seemed to divide itself into two subgroups: those who had established strong service relations with their campus libraries and those who claimed to have attempted such relationships and to have been rebuffed by the librarians. Additional probing revealed that the cause of the rebuff was frequently the library's refusal to provide either special collection space, library staff, or special handling of selected library materials for EOP students.

It is interesting to note that in the two cases where frequent communication appeared to take place, it was channeled through one individual who, in both cases, was a librarian employed by the EOP office. Very little informal communication seems to occur between library and EOP staff.

\section{Library Staff and Service Functions}

Because the provision of library services rests so heavily upon library staff, special attention was focused on the extent to which librarians were specifically assigned the responsibility for serving EOP students and faculty. Among the eight libraries visited, three librarians were identified (in three separate libraries) who devoted a major portion of their time to this group. As was indicated earlier, two of these librarians were employees of EOP offices; only one was employed by the library. All three librarians had, in addition to their EOP service responsibilities, other duties as well, such as collection development and service at the general reference desk. All three were also members of a minority group.

In the course of rather lengthy interviews, each of these librarians emphasized the need for highly individualized service and personal relationships with EOP students and faculty. But given the large numbers of educationally disadvantaged students (ranging from about 500 to over 1,500 ) and the very limited number of library staff specifically assigned, each of these librarians expressed his or her frustration and doubts as to the general effectiveness of the libraries' efforts. They also expressed concern that while they were able to relate effectively to students who were of the same ethnic or racial background as themselves, they questioned their effectiveness in reaching students of other 
racial or ethnic backgrounds, especially those for whom English is a second language. Library administrators and department heads interviewed indicated that efforts continue to be made to recruit librarians who are members of minority groups, but most admitted that they have been relatively unsuccessful in this regard. In contrast to the academic libraries visited, EOP offices seem to have been very successful in recruiting minority staff. Consequently, communication between library and EOP office must cross not only departmental barriers but also racial and ethnic gaps.

In the two cases where librarians were employed by the EOP office, services were more fully developed and ranged from special orientation tours and lectures (including taped tours) and library instruction integrated with basic communication skills courses to programs wherein students receive supervised "hands-on" experience in using reference sources as well as individual counseling and tutoring by EOP librarians. In addition, the EOP librarians regularly participated in classroom instruction by teaching techniques of bibliographic research which focused on the content of a particular class session. In the case where the librarian assigned to work with EOP students and faculty was an employee of the library, services were not as developed or contact as frequent. However, relationships were being established and services planned.

Each of the three librarians who had EOP responsibilities emphasized that the success of their efforts depended in large measure on their individual relationships with EOP faculty and staff. They believed that the emphasis given and importance attached to the library by EOP faculty is readily seen in their students, a view which also finds support in the Monteith College Library experiments. $^{3}$

In the five remaining libraries, where specific staff were not assigned to devel- op services for EOP students, a wide variety of attitudes was found. Most, if not all, of the library directors interviewed expressed genuine concern over their libraries' response to the needs of EOP students. Various types of services had been tried (especially after the student unrest of the late 1960s), but none had been evaluated and most were subsequently dropped for one reason or another. The following are illustrative of the types of services offered: two of the five libraries developed special guides to racial or ethnic literature; four provide bibliographic instruction programs at faculty request; two libraries attempted a course in bibliographic instruction for credit, but it was dropped; and one library operates a term paper clinic. None of these services was specifically designed for EOP students.

An assumption which seems to underlie most of these programs is that students are students. These libraries have not recognized the special needs of educationally disadvantaged students and established appropriate services to meet these needs. Obviously, the identification of these needs is by no means an easy task. Indeed, it is very difficult even to identify EOP students. This may be due in part to the university's desire to assimilate them as quickly as possible into the mainstream of academic programs, as well as to the fact that EOP students are not concentrated only in freshmen classes. Because many of the colleges visited serve as transfer or senior colleges for junior and community colleges, educationally disadvantaged students may be found at freshman, sophomore, and junior levels. Library services, therefore, which are aimed at the first-year college student are probably missing students at these upper levels.

\section{Collections}

Not one of the eight libraries studied had established special collections for 
their educationally disadvantaged students. The three librarians who were specifically assigned EOP responsibilities did maintain small office collections of relevant materials, especially paperbacks. These collections, however, were not the result of library policy, and to some extent they existed outside the formal structure of the library. One librarian (employed by the EOP office) reported that the library's policy prevented the purchase of textbooks. As a result, she maintained her own office collection of texts and workbooks which she personally circulated to EOP students.

When queried about special collections, most library administrators mentioned the large budgets allocated to the development of ethnic studies collections. They tended to equate these collections with the needs of EOP students. Clearly there is frequently a relationship between the two, but the needs of these students for remedial materials may not be met by such collections. For example, books dealing with effective study and communication skills, or those which attempt to correct reading disabilities, might not be included within these collections.

A related problem was the lack of audiovisual resources within the library. None of the libraries studied had an integrated library-media facility (although a few libraries did have audio facilities). Perhaps as a result of this separation, those service programs designed for educationally disadvantaged students did not utilize the electronic media, the only exception being a library tour recorded on cassette tape.

The study also attempted to determine whether EOP faculty were able to contribute in the collection development process. In the case of those institutions which had EOP librarians, these librarians served as liaison between the library and EOP faculty, and titles recommended for acquisition were usually channeled through them. At two of the remaining five libraries, some EOP faculty assumed they should send their requests to the ethnic studies librarian, although none reported doing so. It is interesting to note that library administrators at these two institutions also assumed that EOP departmental requests would be received by their respective ethnic studies librarians. For the remainder of the libraries, no formal mechanisms for EOP faculty input could be discovered.

\section{ConCLUSION}

To summarize, three libraries out of eight provided special programs and special staff to service EOP students and faculty. Only one library, however, assigned a regular, full-time librarian to this group; at the other two libraries the librarians were employed by the EOP offices. Administrators of the five remaining libraries seemed genuinely interested in the problem, but cited a variety of reasons or excuses why their respective libraries could not provide special services. Yet it is precisely these services which appear to be needed. According to the president of City College of New York:
A library, if it is to be a good and use- ful one, must be one of the most dy- namic resources of a modern college or university. . . . it must, in addition to its traditional roles, be responsive to the new demands made upon it by the Open Admissions Program. A ma- jor aspect of this is the development of new modes of instruction in library use for beginning as well as for ad- vanced students. ${ }^{4}$

It is interesting to speculate on the reasons for the rather limited library effort with respect to educationally disadvantaged students. It is undoubtedly very difficult for large bureaucracies such as libraries to change, and response to the educationally disadvantaged obviously demands institutional change. 
From an organizational point of view, Holley found very little difference between urban and rural university libraries. ${ }^{5}$ From the standpoint of services, Haro states that academic libraries have never been noted for their willingness to accept innovative suggestions and implement change from outside sources. Changes in service policies and programs, when they occur, tend to originate only from internal sources. ${ }^{6}$

But some of our urban public libraries have demonstrated that institutional change is possible, and given effective leadership and firm commitment, innovative services have been developed for the disadvantaged. Perhaps no other group of students has ever needed academic library services more than the educationally disadvantaged.
Some have translated these needs and their frustrations into demands on the library that may appear to be impulsive, strident, and economically impossible to some libraries; but, in fact, these demands hold profound significance for the very future of ethnic minority groups, as well as for society as a whole. $^{7}$ If academic libraries are sincerely interested in meeting their service responsibilities to these students, new priorities must be established, a sense of mission must be communicated, and fresh and innovative services must be instituted. There are obvious risks in such a venture-personal and institutional-but these can be met by strong leadership and an appreciation of the extraordinary range of possible rewards.

\section{References}

1. E. J. Josey, "The Role of the Academic Library in Serving the Disadvantaged Student," Library Trends 20:436-42 (Oct. 1971).

2. George W. Whitbeck, The Influence of Librarians in Liberal Arts Colleges in Selected Decision-Making Areas (Metuchen, N.J.: Scarecrow, 1972).

3. Patricia B. Knapp, The Monteith College Library Experiment (Metuchen, N.J.: Scarecrow, 1972).

4. Robert E. Marshak, Problems and Prospects of an Urban Public University (New York: City College, 1973), p.93.

5. Edward G. Holley, "Organization and Administration of Urban University Libraries," College \& Research Libraries 33:180 (May 1972).

6. Robert P. Haro, "Change in Academic Libraries," College o Research Libraries 33:97 (March 1972).

7. Robert P. Haro, "Academic Library Services for Mexican Americans," College \& Research Libraries 33:455 (Nov. 1972). 